\title{
DIE PLEK VAN DIE VAKDIDAKTIEK BY ONDERWYSERSOPLEIDING
}

Vakdidaktick worstel al baie jare lank om 'n regmatige plek in die son te kry. Dat die belang van vakclidakticke die afgelope dekade deur sommige instansies ingesien is, kan seker aan die stigting van afsonderlike departemente vir vakclidakticke binne die fakulteite van Opvoedkunde aan sommige universitcite toegeskryf word. 'n Onlangse vakdidakt ieksimposium deur die Departement Didaktick en Vergelykende Opvordkunde van UNISA wat deur vakdidakt ici vanoor die hele land en buurstate bygewoon is, het die miskende deelwetenskap van die Opvoedkunde permanent op die kaart geplaas. Waarom dan die nuwe belangstelling in dic vakdidaktieke?

- Dit spruit uit ' $n$ verset teen die tradisic dat die besondere vakdepartement vir sy vakdidaktiek verant woordelik was. Vakdidakt ici is binne dic stelsel as handige persone beskou om oral na gelang die besondere departement se behocftes te gebruik en met betrekking tot tyd en inset kon daar nie op hoogte gebly word met die ontwikkeling van die vakdidaktiese teoric nic. Hierdic toedrag van sake was in sommige gevalle grootliks daarvoor verant woordelik dat vakdidakt iek in 'n blote resepmatige aanbieding verval het.

- Navorsing in die Onderwyskunde het ook getoon dat die kwaliteit van vakonderrig op skool grootliks saanıhang met die kwaliteit van vakdidaktiese opleiding aan onderwysstudente.

- Die onaanvaarbare bewering dat vakdidakt icke in vergelyking met ander declwetenskappe van die Opvoedkunde ' $n$ agterstand het, is onwaar. Eerstens is die vakdidaktiek so oud soos dic onderriggeskiedenis van daardie besonderc vakwetenskap; tweedens het die kwaliteit van navorsing in dic jongste jare bewys gelewer dat dit 'n waardige deelwetenskap van die Opvordkunde geword het.

- Geclurende die afgelope kwartecu was daar dwarsoor die wêreld 'n geweldige aanvraag na onderwys en veral hier te lande is die vraag ongekend, byvoorbecld in die jaar 2000 word verwag dat ongeveer 180000 Swartleerlinge hulle vir dic matrikulasie-eksamen sal aanmeld. Die pogings wat dus aangewend word om die standaard van onderwys te verbeter, sal toenemend gerig wees op verbeterde programme vir die opleiding van onderwysers. 
Opvoctkundiges wil sonis himme dic omvang van dic Vakelidaktick 'n mindere rol aan die vakwetenskap torken. "n Wetrnskaplik gefundecrde kennis van dic betrokke vak is 'n vereiste, want dic struktuur van dic vak determincer ook dic verbesondere didaklick. Hinne dir terrein van die Vakcliclaktick moet die doel en struktuur van die vakwetenskap 'n mecr prominente piek kry. So sal 'n geintegrecrde literatuurbeskouing 'n duidelike vaktipiese cllck op dic diclaktick van dic bepaalcle vak hê. Hy moedertaalonderrig sal dic doel anders wees as by dic van die tweede taal of vrecmde taal; vansellsprekend sal dit die didaktick bepaal. Die vakwetenskap word ook vamuit 'n bepaalde religieuse gronelmotief bestudecren gë̈valueer en die didaktiese situasic sal vanuit die bepaalde lewensbeskoulike perspekticl lantecr word.

\section{- Lie pleh uan dic inakdidalick}

Vakdiclaktick is 'n declwetenskap) van dic ()pvoedkunde en het suiwer betrekking op onderwysopleiding en dic mate wat die verworwe kennis en vaarlighede later in dic skoolpraktyk deur onderwysers toegepas word. Verder behoort bruikhare navorsingsresultatc deur dic vakdidaktici vir praktisereude onderwysers deur middel van vakverenigings aan oudstudente oorgedra te word. Dat Vakdidaktick 'n suiwer toxge paste wetenskap) is, is ook net gedecltelik waar. Alboewel die Vakdidaktick 'n verbesondere didaktick is en onderwyskundig tocgespits is, is dit $\mathrm{tog}$ afhanklik van die uitgangspunte en navorsingsresultate van die ander deelwetenskappe van die ()pvoedkunde. Hierdic interalhankliklıcid is natuurlik geldend vir elke alsonderlike declwetenskap) van die (Opvocdkunde. I) Vakdiclaktick as declwetenskap van dic (Opvoedkunde moet dus sy eic prinsipiële en onderwyskundige tcoretiese begronding he. I)it moet ook in staat wees om sinvolle vernuwing en navorsingsresultate betekenisvol vir die praktyk te maak.

\section{- I aak en terrcin nan l'akdidaktiek}

Dit is noodsaaklik om lyy onderwysopleiding 'n werkloare model vir dic vakdidakticke to hê. Iierstens is dit noodsaaklik om orvoleuling met I)idaktiese (Opvocelkunde en Onderwyskunde te verhocel; tweedens om dic verbesondering van aspekte van dic l)idaktiese (Opvoedkunde op'n spesilicke vak toe te pas, maar steeds crkeming an die belangrikheid van die aard en struktuur van die vak tc gec. Die vakdidaktikus, anders as die dosent in dic ander deelwetenskappe van dic (opvoedkunde en dié in die vakwelenskappe, moct kumdigheid verwerf nic net in sy bepaalde vak- 
welcnskap nic, maar ook in die: Didaktiek en ()nderwyskunde. Nagraadse opleiding in dic bepaalde vakwrenskap tot op dic $M$-vlak gepaard met in l3. lifl-graad of andersom, blyk na 'n bevedigende tocrusting vir die vakdidaktikus te wees.

D ie meegaande skematiese voorstelling belig dic omvang vandic lerrein van dic vakolidaktieke. Hieruit is dit duidelik dat die vakditlaktieke as deel-

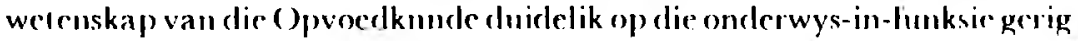
is. Vakdiclakticke behels nie teoretiese opvorelkumdige speckulasies of voortsetting van inhoudsgegewe oor die vak nie. Vakdiclaktick morl vamuit 'n bepaalde lewensbeskoning angebied word en die vaktipiese lecrinlonud kan allecnlik in alhanklikheid van alle declwetenskappe van die ( puocelknnde, maar veral van die verbesomblere Didaktiek ell dir tocgespitste ( )nderwyskunde aangebied word. Die fokuspmut van die vakelidakticke is dic onderwyspraktyk on die onderwysstndent word deur sy opleiding op) wetcuskaplike wyse deur die vakdidaktikus legelci sodat hy cenclag kemuis van 'n vakwetenskap (Afrikaans, lingels. ens.) vrughaar aan die lecelinge kan ondersig.

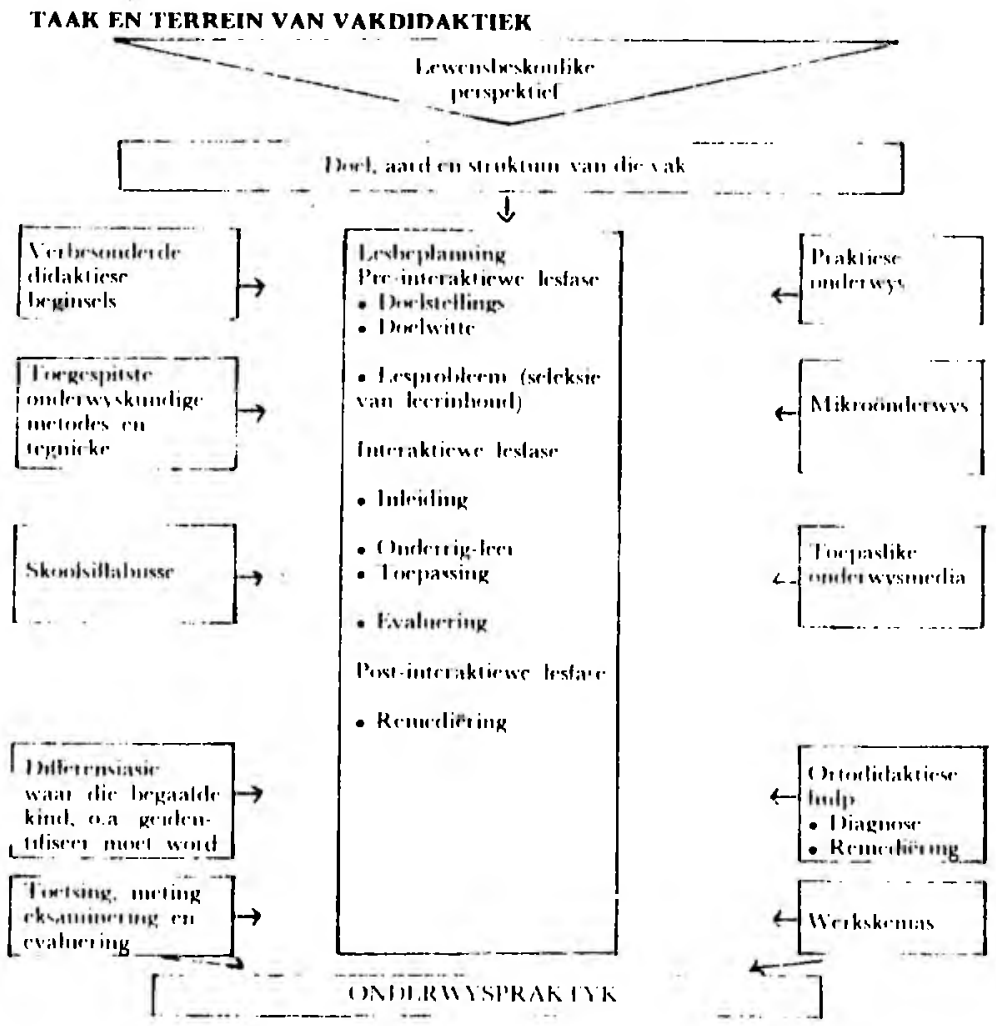

